\section{ECUs for the Unit Fee}

The Executive Committee's proposal to change the unit fee to $9.76 \mathrm{ECU}$, based on the prevailing SFR-ECU exchange rate, was discussed in depth. A fee of 9.1 ECU was finally voted, it having been agreed by a show of hands that any value below the proposed fee implied a reduction and thus required the support of three out of four votes cast, with only IOM and national society representatives voting. Rounding up to 10 ECU (O. Poulsen, Copenhagen) and a decrease to 8.80 ECU, based on the rate that prevailed when the new EPS Constitution came into force (V. Häselbarth, Bad Honnef), were proposed. A compromise would maintain the support for east and central Europe while reducing the impact of the strong Swiss franc (E. Jakeman, Malvern), given that averaging backwards in time made little sense (E. Osnes, Oslo), some adjustment for inflation was reasonable (C. Sébenne, Paris) and fixing a particular day was arbitrary (C. Matos Ferreira, Lisbon). Council also agreed with the President's proposal that the unit fee be reexamined once the impact of the move to Mulhouse had been assessed.

\section{Various Activities Highlighted}

The reports by representatives of the various EPS Boards and Committees highlighted Internet-based activities as a major area of interest. Several Divisions and Interdivisional Groups have launched WWW-based newsletters. EPS initiatives are managed by the Internet Coordination Group which has recently launched a scheme to improve links between national WWW sites at the institute and society levels. The Group received the go-ahead to explore the possibility of making Division and Group membership lists available via WWW.

Physics teaching will receive a major boost once the European Physics Education Network (EUPEN) is in place (C. Matos Ferreira, Chair, Physics Education) and it would be wise to incorporate EUPEN into the EPS strategy (O. Poulsen). However, obtaining further funding for the European Union (EU)-supported European Mobility Scheme for Physics Student (EMSPS) to cover every east and central European country was proving difficult (H. Ferdinande, Mobility Committee) and reducing costs by having the administration contracted out to a national society may help (I. Strzaltkowski, Warsaw). But the demand remained clear, especially since an impressive $70 \%$ of students moving within the scheme

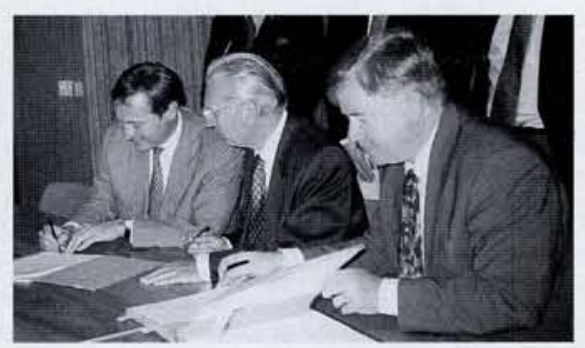

The EPS President, H. Schopper (seated in the middle), signing the framework agreement with J.-M. Bockel, Mayor of Mulhouse (left) and G. Prado, President of the Universite de Haute Alsace (right), that covers the establishment on 1 January 1997 of the EPS Secretariat at the Technopôle de la Mer Rouge on the outskirts of Mulhouse. The ceremony took place in Mulhouse on 29 May in the presence of representatives of the various local and regional authorities and organizations that are partners in the agreement.

have been able to transfer course credits to their home universities.

The very positive response to the launch of the Eur Phys designation clearly showed the needed for enhancing the professional recognition of individual physicists in modern economies (M. Peter, Chair, Register Commission). So it was important to help physicists from the economically weaker regions of Europe meet the cost of registering by scaling fees (P.H. Melville, Chair, Applied Physics and Physics in Industry) and having them in ECUs (G.C. Morrison, Birmingham), by establishing a solidarity fund once there was sufficient income, and by extending the registration period (J. Bessa Soussa, Porto) if this was compatible with the need to demonstrate satisfactory retraining. In the meantime, more information must be circulated via national societies, especially with regard to the impact of professional recognition on job opportunities (R. Morgenstern, Chair, Atomic and Molecular Physics). A proposal (P.H. Melville) to examine the possibility of having more than one physics-based EPS member society in a country, so that the scheme can be promoted more widely, was accepted.

The Solidarity Fund that supports participation at EPS conferences using a levy had set off to a good start with funds for 33 grants available this year (R. Pick, Chair, Conference Committee). But EUsupport had become more difficult to obtain since rules encouraged participation by young people while the reviewing of each European Research Conference (physics ERCs are proposed by Divisions) led to uncertainty about the ERC series.

Summaries of the decisions taken by Council (and by the Executive Committee that met on 21 March) were reported in News from EPS (March-April 1996). They can also be found on EurophysNet's europhysics news extra (http://epswww.epfl.ch)

\section{SEVILLE 1996}

EPS-10 General Conference Trends in Physics

Seville; 9-13 September 1996

- Many special meetings and events will take place in parallel with the General Conference.

- Fully updated details are given on the EPS EurophysNet WWW service (http://epswww.epfl.ch)

\title{
A New Qualification for Physicists
}

\section{Peter, Chair, Register Commission}

The designation European Physicist (abbreviated as Eur Phys) is a new qualification for physicists that was established by the EPS in 1995. The fundamental reason for its creation stems from the fact that times are changing, and are becoming harder for many physicists. Gone are the days when a permanent position is offered to most successful students upon graduation from university. Permanent employment may become the exception rather than the rule, so physicists, like most pro-

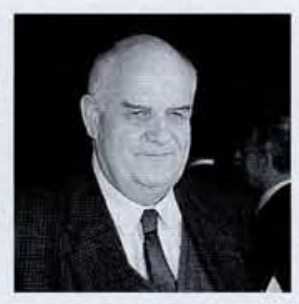

Martin Peter, the Chairman of the European Register of Physicists, is with the Physics Department, Geneva University. He has served as the Head of the Department and as the University's Rector. fessionals, have to reeducate, and to adapt to a new career more than once.

The reason for this evolution is to be found in the changing nature of the European economy, which is moving increasingly from the secondary sector into services. One might have hoped that this trend would increase rather than decrease research activities. To a certain extent this is indeed happening, but at the same time the nature of these activities is also changing since industrial research is tending to move to where manufacturing has gone.

In this changing climate, the possibility to adapt one's activities becomes an important asset. Adaptation includes continued education and the ability to take initiatives in organizing work for oneself and for others. It also includes mobility. Mobility is facilitated by professional qualifications which are widely recognised. 


\section{Professional Qualifications}

Formal professional qualifications exist in many occupations. Generally, a person receives such a qualification on the basis of a combination of academic attainments and experience in a profession. Where they exist, however, there are for some professions wide differences between formal systems of recognition, in the body awarding the qualification, in the criteria applied, and in the code of conduct an applicant is expected to abide by.

Such differences may restrict the opportunities for citizens of a given country to exercise their profession elsewhere. In the case of the European Union (EU), the European Commission, which has been active for some time in promoting the mutual recognition of academic degrees, is now also taking initiatives regarding professional qualifications. The EPS includes EU countries as well as most of the European countries that are not part of the Union. It will therefore be a special challenge for the EPS to establish for its Eur Phys qualification widespread and efficient recognition both within the EU and between the EU and non-EU countries.

National societies, institutes and associations covering various fields of science and technology have collaborated in establishing several European Registers for qualified professionals. In physics, the situation is somewhat different from that found elsewhere owing to the existence of the EPS which one can join directly or participate in through a national society. Given its unique position, the Society has set up the European Register of Physicists and the necessary procedures for handling applications for entry on the Register.

\section{Requirements for Admission}

To be admitted to the European Register of Physicists, the academic qualification must be in physics or in a physicsrelated area which is acceptable to the Register Commission. It must have involved the equivalent of at least three years full-time university-level education.

Evidence of at least two years of appropriate experience gained in a professional capacity after graduating is also required. This experience could include research and development, project management, supervision and the training of others, and safety management.

The remaining period, which must have lasted for at least two years, may consist of either education leading to an academic qualification or appropriate experience involving responsibilities and

\section{Status of the European Register}

Today it can be said the designation European Physicist exists and that the Register of European Physicists is already a going concern. A total of 34 Eur Phys have been registered so far.

Some applicants have been asked to resubmit applications once they have gained more experience; others have been asked to provide additional information. The Register Commission is aware that the application and registration fees may present difficulties for some applicants. The problem is under study, and proposals will be made in due course to the Council of the EPS. Eventually, the operation of the Register should become self-supporting, and render possible the establishment of a Eur Phys Solidarity Fund.

National physical societies have been asked to help ensure that the European Register of Physicists becomes well established by:

- making the Register known to their members;

- nominating representatives to the European Regional Monitoring Committee.

deemed satisfactory by the Register Commission. It must also include a period of training during which the applicant has acquired aptitudes or skills needed to exercise in the chosen profession and in a responsible capacity.

These requirements clearly show that Eur Phys is not an alternative to degrees awarded through traditional academic channels. Instead, it is complementary to the hierarchy of academic degrees: it requires evidence for a minimum of practical experience, performance and professional behaviour along with a minimum level of recognised academic training.

\section{The Register}

Those included on the European Register of Physicists are:

- able to use the designation European Physicist and its abbreviation Eur Phys; - kept informed, by means of a section in Europhysics News, the Bulletin of EPS, and a special electronic newsletter, about professional aspects relating to the practice of physics and of developments in the professional recognition of physicists.

Inclusion of a physicist's name will give the public an assurance that the physicist concerned has satisfied the Register's requirements and has agreed to adhere to a Code of Conduct.

The Register is open to all physicists in Europe. For admission it is necessary to produce evidence for the successfully completion of a minimum period of seven years' professional formation, including: - at least three years' university education in physics or in a physics-related discipline to an academic level;

- at least two years' responsible postgraduation experience, which may include a period of training;

- at least two years' additional university education and/or appropriate postgraduation experience.

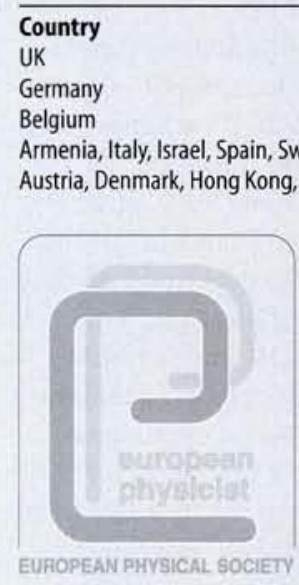

The initial phase of post-graduation experience may include training, whether formal or otherwise, but a candidate will be expected to demonstrate a capacity for independent judgment in work related to physics or its application. The nature of the experience may include research, project management, supervision and training, and safety management. Candidates will be expected to demonstrate an awareness of responsibility to the public when this is implicit in the nature of their work.

A European Regional Monitoring Committee evaluates the application. It is assisted by independent experts familiar with the regions in which applicants have trained and worked. The Committee then makes a short summary and a recommendation to the Register Commission.

The Commission reviews the summary and recommendation to ensure uniform, high standards. If it is satisfied, you will be invited to pay the registration fee of 250.- Swiss francs for admission to the European Register of Physicists for an initial period lasting five years.

Thereafter, registration will be renewable without the need to submit a new application (although you might be asked to update your first application).

You will be provided with a formal certificate of registration. From then on you will be able to use the designation European Physicist.

- Acknowledgments are due to those who thought of the Register, and who believed in it from the start, namely Peter Boswell, Secretary of the Register Commission, Eddy Lingeman, Secretary of the European Regional Monitoring Committee, and last but not least Derek Jefferies who formulated the scheme and is now the coordinator.

- Information and application forms can be obtained on the EPS EurophysNet WWW service at http://epswww.epfl.ch, from national physical societies and from E.W.A. Lingeman, Secretary, European Regional Monitoring Committee, $\mathrm{POB}$ 94395, NL-1090 GJ Amsterdam (ed@nikhef.nl). Tel.: +31 2059221 17; fax: +31 205922165 . 